\title{
Impact of therapeutic and high doses of florfenicol on kidney and liver functional indicators in goat
}

\author{
Jan Muhammad Shah ${ }^{1}$, Toufique Ahmed Qureshi ${ }^{1}$, Tahmina Shah ${ }^{2}$, Qurban Ali Shah ${ }^{3}$, Muhammad Asif Arain ${ }^{3}$,
} Zohaib Ahmed Bhutto ${ }^{3}$, Muhammad Saeed ${ }^{4}$ and Farman Ali Siyal ${ }^{5}$

1. Department of Pharmacology, Shaheed Benazir Bhutto University of Veterinary and Animal Sciences, Sakrand, Pakistan; 2. Department of Dairy Technology, Baqai College of Veterinary Sciences, Baqai Medical University, Karachi, Pakistan; 3. Department of Animal Husbandry, Faculty of Veterinary and Animal Sciences, Lasbela University of Agriculture, Water and Marine Sciences, Uthal 3800, Pakistan; 4. College of Animal Sciences and Technology, Northwest A \& F University, Yangling 712100, China; 5. Department of Animal Nutrition, Faculty of Animal Husbandry and Veterinary Sciences, Sind Agriculture University Tandojam, Pakistan.

Corresponding author: Jan Mohammad Shah, e-mail: dr.jm135@gmail.com, TAQ: tofique_qureshi@hotmail.com, TS: Vetdr.shah@gmail.com, QAS: drshah73@yahoo.com, MAA: asifarain77@nwsuaf.edu.cn, ZAB: bhutto92zohaib@gmail.com, MS: muhammad.saeed@nwsuaf.edu.cn, FAS: drfarmansial@gmail.com,

Received: 03-05-2016, Accepted: 01-09-2016, Published online: 24-10-2016

doi: 10.14202/vetworld.2016.1135-1140 How to cite this article: Shah JM, Qureshi TA, Shah T, Shah QA, Arain MA, Bhutto ZA, Saeed M, Siyal FA (2016) Impact of therapeutic and high doses of florfenicol on kidney and liver functional indicators in goat, Veterinary World, 9(10): 1135-1140.

\section{Abstract}

Aim: The aim of this study was to evaluate the impact of therapeutic and high doses of florfenicol on kidney and liver functional indicators in goat species.

Materials and Methods: Six mature, healthy goats (combine breed and sex) with average weight $25 \mathrm{~kg}$ were selected for this study. The therapeutic (20 mg/kg b.w.) and high doses (40 and $60 \mathrm{mg})$ of florfenicol were administered for 3 days with $24 \mathrm{~h}$ interval. Blood samples were collected at $0,24,48,72,96$, and $120 \mathrm{~h}$ following the each administered dose.

Results: The results showed that the therapeutic dose of florfenicol produced nonsignificant effect on serum urea, creatinine, total protein (TP), alkaline phosphatase (ALP), gamma-glutamyl transferase (GGT) and bilirubin on all timings, and increased $(\mathrm{p}<0.05)$ the serum glutamic oxaloacetic transaminase (SGOT) and serum glutamate-pyruvate transaminase (SGPT) levels for $48 \mathrm{~h}$. Whereas the high doses of florfenicol (40 and $60 \mathrm{mg}$ ) significantly altered the kidney and liver functional indicators in the blood. In contrast with control, the serum urea level was $(p<0.01)$ increased at all timing points. Creatinine values were altered $(\mathrm{p}<0.01,<0.05)$ in increasing manner from 24 to $96 \mathrm{~h}$. The high dose of $40 \mathrm{mg}$ decreased the TP $(\mathrm{p}<0.05)$ for $72 \mathrm{~h}$ and $60 \mathrm{mg}$ persisted same effect $(\mathrm{p}<0.01)$ up to $120 \mathrm{~h}$. The indices of ALP, GGT, SGOT, and SGPT were raised $(p<0.01,<0.05)$ at all timings. The bilirubin indexes also $(p<0.05)$ elevated from 48 to 72 .

Conclusion: It was concluded that the high doses of florfenicol produced reversible dose-dependent effects on functional indicators of kidney and liver such as urea, creatinine, TP, ALP, SGOT, SGPT, GGT, and bilirubin.

Keywords: blood chemistry, florfenicol, goat, liver and kidney function tests, therapeutic and high doses.

\section{Introduction}

Chloramphenicol is broad spectrum antibiotic compound, was employed to curing the numerous infectious diseases caused by bacteria. Florfenicol belonging to amphenicols are broad-spectrum antibiotics commonly used in veterinary as well as in aquaculture to treat the infections caused by bacteria $[1,2]$. These types of antibiotics bind permanently to the $50 \mathrm{~S}$ ribosomal subunit to inhibit the protein synthesis [1]. Nowadays, these antibiotics are restricted simply for specific infectious diseases in veterinary clinics because of their noxious effects on various organs and body systems such as excretory and hepatic. They

\footnotetext{
Copyright: Shah, et al. Open Access. This article is distributed under the terms of the Creative Commons Attribution 4.0 International License (http://creativecommons.org/licenses/by/4.0/), which permits unrestricted use, distribution, and reproduction in any medium, provided you give appropriate credit to the original author(s) and the source, provide a link to the Creative Commons license, and indicate if changes were made. The Creative Commons Public Domain Dedication waiver (http://creativecommons.org/ publicdomain/zero/1.0/) applies to the data made available in this article, unless otherwise stated.
}

were also eradicated due to prolong persistence of their metabolites and residues in the body resulting longterm toxicity [3]. It was a vital requirement to find out novel drugs which would have the similar efficacy in treatment with less adverse effects. Florfenicol is the drug of choice in veterinary field for curing the domestic animals due to its harmless and less toxic properties [4]. Florfenicol is fluorinated derivative of chloramphenicol, acquire the similar features of the parent compound, however, is less blamed to produce harsh and unfavorable effects [5,6]. The florfenicol can be used as an alternative to chloramphenicol. In the body, less amount of florfenicol metabolized due to this reason various high doses of florfenicol were under trial at clinical and laboratory levels [3]. The therapeutic dose of florfenicol produce reversible short-term toxic effects on the kidney and liver functional indices in the piglets. With time after cessation of florfenicol administration these effects gradually return to normal [7]. The recent studies proved that florfenicol can be used as a possible synergistic 
antimicrobial modulator along with many kinds of antibiotic and is effectively kill both Gram-positive and Gram-negative depending on its combination with antibiotic [8]. Previously documented research proved that high dosages of florfenicol produced dose-dependent toxicities such as alteration in kidney and liver functional indicators in various species, in mice [9], horse [10], pig [3,11], chicken [12], and in fish [13], To avoid these toxic effects throughout therapy with high doses, laboratorial periodic estimation of kidney and liver indices should be carried out to get clinically useful stable serum and tissue concentration of drug for prolonged period.

The little is acknowledged about different high doses of florfenicol along with their influence on nephro and hepato toxicity in small ruminants particularly in goat. Although many research reports about the cytotoxicity with high doses of florfenicol, limited studies were found on the liver and kidney functional indicators in farm animals.

The florfenicol was used to treat numerous infectious diseases caused by bacteria. However, the question addresses that the toxic effects of florfenicol on kidney and liver functions in goat, and it's unclear in literature. Therefore keeping in the view the importance of the subject, this study was designed to evaluate the impact of therapeutic and high doses of florfenicol on liver and kidney functional indicators in goat.

\section{Materials and Methods}

\section{Ethical approval}

The research was approved by Animal Ethics Committee of Sindh Agriculture University, Tandojam as per state laws.

\section{Experimental Design}

Six mature healthy local goats (combine breed and sex) were chosen and averagely weighted as $25 \mathrm{~kg}$. Animals were reared at livestock experimental farm, Sindh Agriculture University, Tandojam, Pakistan. Goats were ear tagged and assigned with A-F letters for identification mark. Goats were fed with green forages; concentrates and water were provided on ad libitum basis. The animals were allowed for acclimatization for 21 days before starting of experiment, and during this period animals were dewormetized. Initially, normal or control (C) baseline values of biochemical parameters recognized. The blood samples were drawn aseptically from jugular vein in plane test tubes. The blood samples were transported to the Postgraduate Laboratory of Department of Physiology/Pharmacology, Sindh Agriculture University, Tandojam, Pakistan. The samples were centrifuged at $1500 \mathrm{rpm}$ for $10 \mathrm{~min}$ for serum collection. Serum was stored at $-20^{\circ} \mathrm{C}$ for future analysis of biochemical parameters. The absorbance was detected on ultraviolet spectrophotometer according to wavelength mentioned in kits. The serum total protein (TP) quantified through Biuret method
(Human Company, Germany). Serum urea measured using urea kit (Human, Germany). Serum creatinine detected via Jaffed reaction method (Human, Germany). Serum alkaline phosphatase (ALP), serum glutamic oxaloacetic transaminase (SGOT or AST), serum glutamic pyruvic transaminase (SGPT or ALT), and gamma-glutamyl transferase (GGT) also calibrated by kit methods (Human, Germany). Serum bilirubin measured by Jendrassik-Grof method (Merck Germany).

\section{Drug administration and sample collection}

Florfenicol $\left(\right.$ Naflor $\left.^{\complement}\right)$ obtained from Nawan Laboratory (Karachi, Pakistan) and administered intramuscularly with different dosage regimes. During Phase-I, therapeutic dose $(20 \mathrm{mg} / \mathrm{kg} \mathrm{BW})$ of florfenicol then in Phase-II first high dose $(40 \mathrm{mg} / \mathrm{kg} \mathrm{BW})$ and finally in Phase-III second high dose $(60 \mathrm{mg} / \mathrm{kg}$ $\mathrm{BW}$ ) induced to goats. Each consecutive dose was administered for 3 day with intervals of $24 \mathrm{~h}$. Blood samples were collected at $0,24,48,72,96$, and $120 \mathrm{~h}$ after completion of each dose schedule in each consecutive phase. 0 designated as control (C) exclusive of drug administration. The crossover design with 21 days washout period among the treatments.

\section{Statistical analysis}

All obtained data were represented as means \pm standard deviation mean and evaluated via one-tailed analysis of variance using student edition statistical program. LSD was used to denote significance difference among the florfenicol induced doses and control baseline at various schedules. $\mathrm{p}<0.05$ was set for significance level.

\section{Results}

\section{Serum urea}

Mean values of serum urea with different doses $(20,40,60 \mathrm{mg} / \mathrm{kg} \mathrm{BW})$ of florfenicol at timing points were publicized in Figure-1. Therapeutic dose $(20 \mathrm{mg})$ non-significantly altered the serum urea. At $60 \mathrm{mg}$ dose of florfenicol administration a significant increase $(\mathrm{p}<0.01)$ was observed in the serum urea level from 24 to $120 \mathrm{~h}$. The maximum significant increase of serum urea level at this dose was found at $48 \mathrm{~h}$ of post drug administration. The concentration

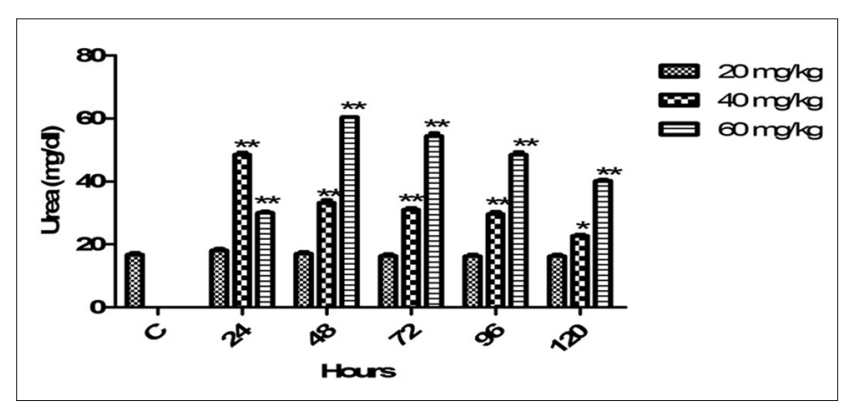

Figure-1: Mean serum urea $(\mathrm{mg} / \mathrm{dl})$ level of six goats obtained after intramuscular administration of florfenicol at the dose rate of 20, 40 and $60 \mathrm{mg} / \mathrm{kg}$ b.w. Significantly different $(* p<0.05, * *<0.01)$ from control values. 
of serum urea was statistically increased $(p<0.01)$ through $24-96 \mathrm{~h}$ and $\mathrm{p}<0.05$ at $120 \mathrm{~h}$ post employed dose of $40 \mathrm{mg}$.

\section{Serum creatinine}

Mean pre- and post-treated value of creatinine with various doses regimes of florfenicol on programed schedule mentioned in Figure-2. Therapeutic dose non-significantly affected the creatinine level. The concentration of serum creatinine has significantly platuead $(p<0.01)$ from 24 to $72 \mathrm{~h}$ and $(\mathrm{p}<0.05)$ at $96 \mathrm{~h}$ after induction of $60 \mathrm{mg}$ dose. $40 \mathrm{mg}$ dose produced significant $(\mathrm{p}<0.01)$ effect via increasing the serum creatinine at $24 \mathrm{~h}$ and $\mathrm{p}<0.05$ from 48 to $96 \mathrm{~h}$. The level of creatinine was gradually returned to control baseline value at $120 \mathrm{~h}$.

\section{Serum TP}

As compared to control, the therapeutic dose of florfenicol non-significantly altered the serum TP level. The reduction in serum protein level $(\mathrm{p}<0.05)$ was noticed from 24 to $72 \mathrm{~h}$ with $40 \mathrm{mg} / \mathrm{kg}$ medicated dose of florfenicol (Figure-3). While another high dose $(60 \mathrm{mg} / \mathrm{kg})$ produced decreasing effect on the $\mathrm{TP}$ at $24 \mathrm{~h}(\mathrm{p}<0.05)$, and persisted highly significant effect from 48 to $120 \mathrm{~h}$ post induction. With $40 \mathrm{mg}$ dose, the serum TP concentration was started to return toward normal values at $96 \mathrm{~h}$.

\section{Serum ALP}

The average values of ALP treated with therapeutic and high-dosage regimes on various schedules were depicted in Figure-4. $20 \mathrm{mg}$ dose non-significantly altered the serum ALP values. The increased $(p<0.01)$ ALP level was observed since $24-120 \mathrm{~h}$ post $60 \mathrm{mg}$ treated dose. While $40 \mathrm{mg}$ dose altered ALP indices $(p<0.01)$ at $24 / 48 \mathrm{~h}$ and $(\mathrm{p}<0.05)$ from 72 to $120 \mathrm{~h}$. Both doses produced persistent effect and ALP level was not reversed to control baseline values even up to the $120 \mathrm{~h}$ post drug therapy.

\section{Serum GGT}

The mean control and post dosages values of serum GGT on different timing points are mentioned (Figure-5). Non-significantly effect was noticed on GGT with therapeutic dose. The highly significant effects on GGT level was observed in $60 \mathrm{mg}$ dosage regime on all timing points. The GGT level was significantly $(\mathrm{p}<0.01,<0.05)$ boosted at all timings followed by dose of $40 \mathrm{mg}$. The effect of both high doses was persisted, and level of GGT was not backed toward control baseline.

\section{SGOT}

The average SGOT indices after administration of different doses of florfenicol with various timings publicized in Figure-6. Therapeutic dose significantly $(\mathrm{p}<0.05)$ raised SGOT level at $24 \mathrm{~h}$. The both high doses significantly $(\mathrm{p}<0.01 ;<0.05)$ increased the SGOT level all timing points. The high doses persisted effect on SGOT and its level not returned to control indices even up to $120 \mathrm{~h}$ post drug medication.

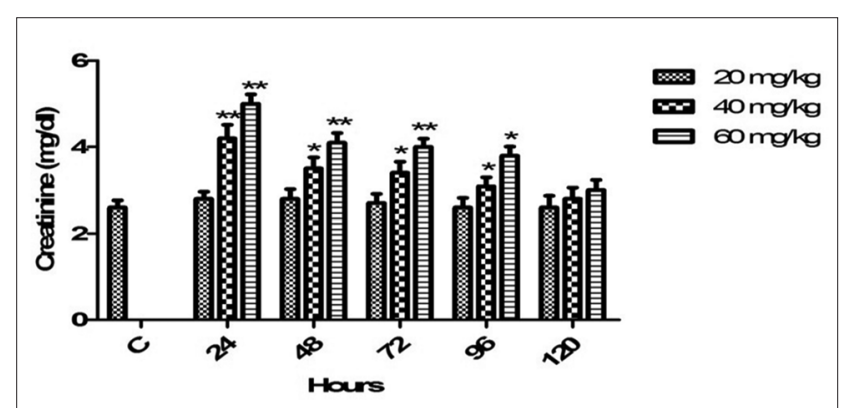

Figure-2: Mean serum creatinine (mg/dl) level of six goats obtained after intramuscular administration of florfenicol at the dose rate of 20,40 and $60 \mathrm{mg} / \mathrm{kg} \mathrm{b.w}$. Significantly different $(* p<0.05, * *<0.01)$ from control values.

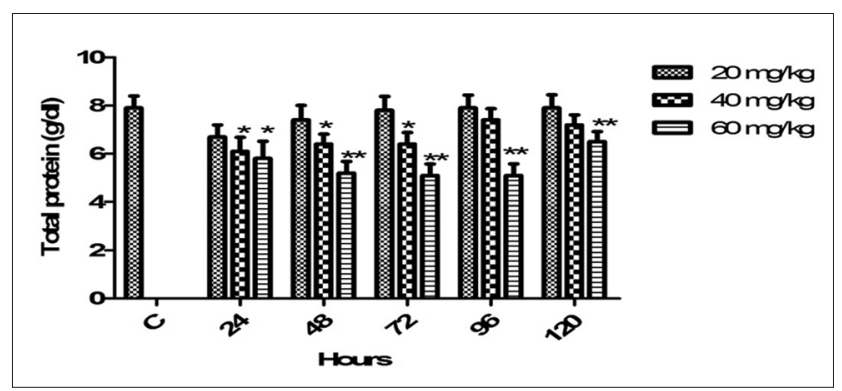

Figure-3: Mean serum total protein ( $\mathrm{g} / \mathrm{dl}$ ) level of six goats obtained after intramuscular administration of florfenicol at the dose rate of 20,40 and $60 \mathrm{mg} / \mathrm{kg} \mathrm{b.w.} \mathrm{Significantly}$ different $(* p<0.05, * *<0.01)$ from control values.

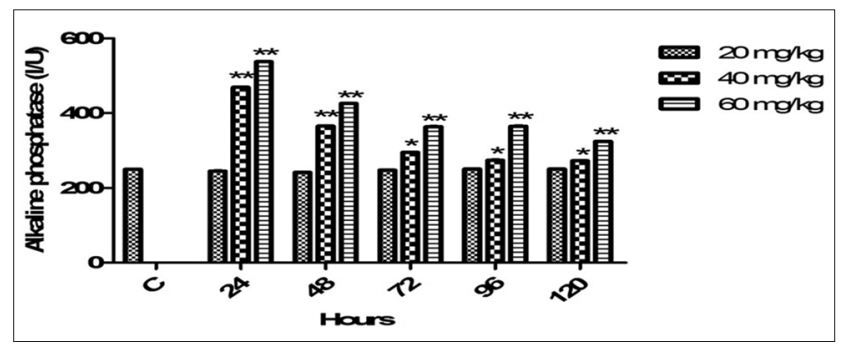

Figure-4: Mean serum alkaline phosphatase (I/U) level of six goats obtained after intramuscular administration of florfenicol at the dose rate of 20, 40 and $60 \mathrm{mg} / \mathrm{kg}$ b.w. Significantly different $(* p<0.05, * *<0.01)$ from control values.

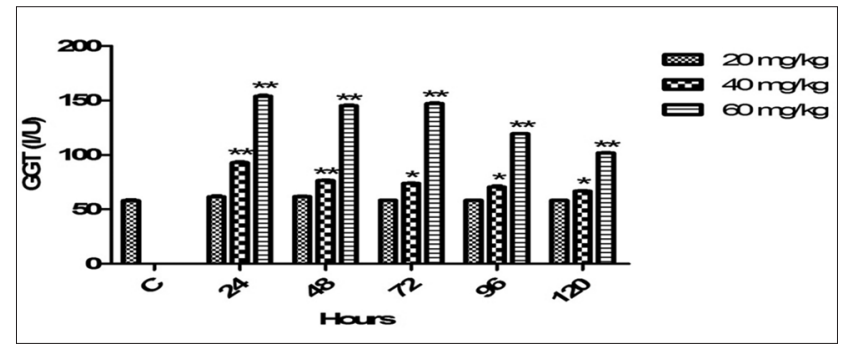

Figure-5: Mean serum gamma-glutamyl transferase (I/U) level of six goats obtained after intramuscular administration of florfenicol at the dose rate of 20,40 and $60 \mathrm{mg} / \mathrm{kg}$ b.w. Significantly different $(* \mathrm{p}<0.05, * *<0.01)$ from control values.

\section{SGPT}

The average SGPT values at various timings medicated with therapeutic and high doses of florfenicol mentioned in Figure-7. In comparison with control, 
therapeutic dose significantly $(\mathrm{p}<0.05)$ increased the SGPT indices at 24 and $48 \mathrm{~h}$. The both high doses raised the SGPT values significantly $(\mathrm{p}<0.01,<0.05)$ at all timing points and produced effect persistently.

\section{Serum bilirubin}

The mean serum bilirubin indices after medication of various doses of florfenicol with planned timings had presented in Figure-8. The therapeutic dose non-significantly changed the values of serum bilirubin. Both high dosage regimes significantly $(\mathrm{p}<0.05)$ raised the level of bilirubin from 24 to $72 \mathrm{~h}$. The values of bilirubin returned toward control baseline from $96 \mathrm{~h}$.

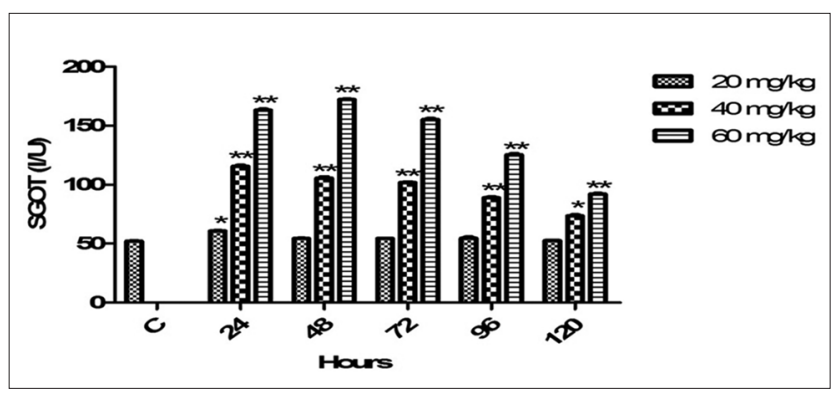

Figure-6: Mean serum glutamic oxaloacetic transaminase (I/U) level of six goats obtained after intramuscular administration of florfenicol at the dose rate of 20,40 and $60 \mathrm{mg} / \mathrm{kg}$ b.w. Significantly different $(* \mathrm{p}<0.05, * *<0.01)$ from control values.

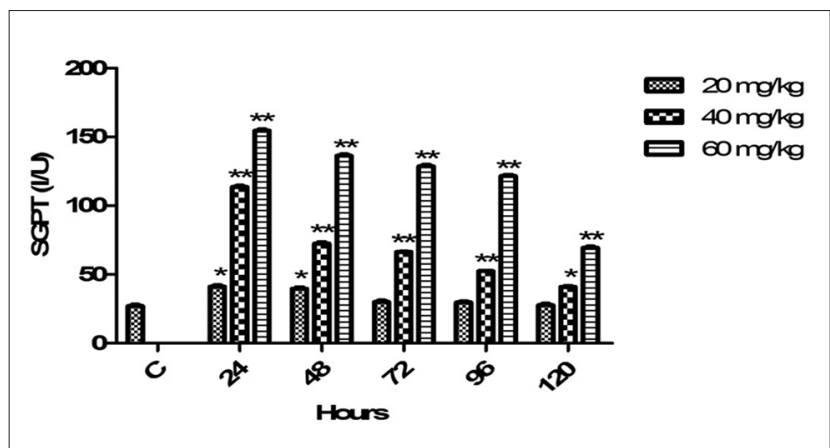

Figure-7: Mean serum glutamate-pyruvate transaminase (I/U) level of six goats obtained after intramuscular administration of florfenicol at the dose rate of 20,40 and $60 \mathrm{mg} / \mathrm{kg}$ b.w. Significantly different $(* \mathrm{p}<0.05, * *<0.01)$ from control values.

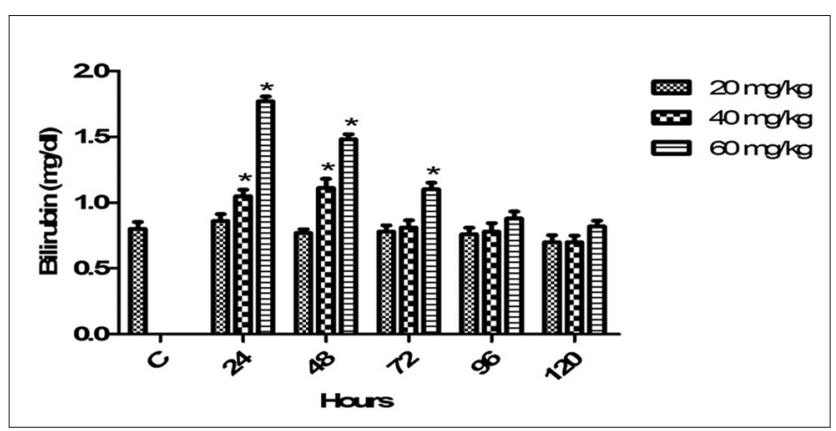

Figure-8: Mean serum bilirubin $(\mathrm{mg} / \mathrm{dl})$ level of six goats obtained after intramuscular administration of florfenicol at the dose rate of 20, 40 and $60 \mathrm{mg} / \mathrm{kg}$ b.w. Significantly different $(* p<0.05)$ from control values.

\section{Discussion}

Therapeutically, florfenicol is extensively practiced in farm animals to cure the infection and also used for prophylaxis as well as feed additive. The main side effects were unusually observed with therapeutic dose $(20 \mathrm{mg} / \mathrm{kg}$ b.w.) of florfenicol in farm animals. One reported side effect is the elevated bilirubin concentration [10]. By employing high dosage treatment with florfenicol is of great significance to attain valuable plasma and tissues concentration of drug for longer period rather than regular repeated dosing. Although, before using high dosage regimen various side effects of florfenicol on major organs necessarily considered. For that reason, we examined the laboratorial assessment of kidney and liver functional indices. The both high doses of florfenicol elevated the indices of serum urea level which coincide with previously reports $[3,11,14]$. Whereas, the therapeutic dose produced no effect on urea in this study according to previous report in horse [10]. The urea is produced through deamination of proteins, in the liver and high doses of florfenicol possibly reduced the protein level via triggering the catabolism of protein, and interference with the urea excretion process (glomerular filtration) in kidneys finally retention of urea in the blood [15]. The effect of florfenicol on nitrogen metabolism is probably a reflection of the systemic anti-anabolic action via diminished amino acids incorporation into protein, thus leads an elevation of blood urea [16]. As indicated urea is the soluble and comparatively less toxic end product of protein breakdown formed from ammonia in liver through urea cycle and if protein- nitrogenous and non-protein nitrogenous byproducts not removed from body, they may finally lead to azotemia [11]. The high doses of florfenicol increased serum creatinine levels which were closely matched with previous studies in pig, alpaca, and in fish $[11,14,17]$. Creatinine is nonprotein nitrogenous product of creatine (phosphocreatine) produced from muscles. Florfenicol might be trigger creatine in muscles leading to elevated level of creatinine in the blood [18]. Another study also confirmed that florfenicol cause degenerative changes in tubules of kidney which ultimately prevent the excretion of creatinine [19]. It is also speculated that florfenicol caused damage to renal tubular cells lead to tubular obstruction, which alter the renal microcirculation finally retention of creatinine level into the blood [20]. Therapeutic dose produced no effect on protein level which coincided with earlier report [10]. High doses of florfenicol decreased the values of serum protein. In microbes, florfenicol inhibit the protein synthesis in the translation stage by binding with specific sites of messenger RNA before exposure to ribosome [21]. The previous studies demonstrated that florfenicol interference with mitochondrial protein synthesis due to similarities between of prokaryotic ribosomal and mitochondrial ribosomal subunits in eukaryotes $[22,23]$. It 
is speculated that this similarity may be the base to alter this variable in host, when high doses of florfenicol medicated. Outcomes regarding serum protein level coincide with earlier reports [11,17]. The high doses of florfenicol persistently raised the indices of ALP may be associated with high concentration of drug in the blood. One study confirmed that moderated high doses reversible altered the small magnitude of ALP, which proved that concentration of drug also important [24]. ALP is found in majority of tissues (kidney, bone, and placenta) in the body but more concentrated in liver. It is a membrane-bound enzyme present on biliary epithelial cells and hepatocytes. It is documented that florfenicol induce histological changes in hepatocytes that disturb a cellular permeability process in cell membrane, may allowing the escape of this enzyme into the serum [25]. It is speculated that florfenicol may causes biliary obstruction, and in turn injury to the bile duct epithelium, or cholestasis resulting an increased synthesis of ALP in hepatic cells that lead to its high concentration in serum [26]. During the current study florfenicol elevated the values of GGT. Liver is the primary source of GGT, whereas this enzyme is a membrane-bound protein present on hepatocytes, and biliary epithelia plays a key role in cyclic regeneration of amino acids from extracellular glutathione for synthesis of intracellular glutathione, and cellular detoxification. It is possible florfenicol high concentration may cause cholestasis, then partial obstruction of intrahepatic bile duct and biliary epithelial insult, and ultimately increase in GGT activity [26,27]. Florfenicol might be damage hepatobilliary cells, and elution of damaged membranes triggers the GGT synthesis which in turn cause alteration and increased the half-life of this enzyme [28]. SGPT and SGOT enzymes present in numerous tissues (kidneys, heart, skeletal muscle, brain, and red blood cells) of the body but prominently in liver parenchyma. The high doses of florfenicol produced persistent effect and elevated the SGPT and SGOT levels in the blood due to the presence of high concentration of drug for a longer period. Florfenicol may damage and cause leakage of hepatocytes cell membrane, resulting the releasing of aminotransferases from hepatic cell that leads their increased concentration in blood [29]. Florfenicol may also supposed to induce hepatic hypertrophy leads to induction of hepatic enzymes (functional hypertrophy) and other profound changes that often accompany this phenomenon of increased transaminases [30]. High doses of florfenicol may also be speculated that increased rate of synthesis of SGOT and SGPT altered the half-life of these enzymes in serum [28]. In this study, the results of ALP, GGT, SGPT, and SGOT indices were according to previous documented researches $[3,11]$. The bilirubin is the breakdown product of normal heme catabolism which is a principal component of red blood cell. Bilirubin plays main physiological role as a cellular antioxidant. In liver bilirubin is conjugated with glucuronic acid via glucuronyl transferase then become soluble bilirubin diglucuronide. It is suggested that elevation of bilirubin was might be the effect of drug with conjugating activity of bilirubin in the liver [10]. Florfenicol may impair hepatic bile flow caused accelerated red blood cells destruction or decreased bilirubin metabolism [31]. The hepato cellular injury and ischemia are other possible reasons for retention of bilirubin into the blood [32]. The increased level of bilirubin matches with previous study [10]. In conclusion, both high doses of florfenicol produced adverse effects on kidney and liver in dose dependent fashion. The outcomes of this study can be guidance for veterinary practitioner in decision making for choosing high dose therapy regarding treatment of bacterial infections. However before usage of high doses, laboratorial analysis of kidney and liver functional indicators must be followed up throughout treatment phase particularly in debilitate farm animals such as goat and sheep.

\section{Conclusion}

It was concluded that the high-dosage regimes of florfenicol produced reversible dose-dependent effects on functional indicators of kidney and liver such as (urea, creatinine, TP, ALP, SGOT, SGPT, GGT, and bilirubin). In the light of these results, it is recommended for the future that high doses of florfenicol evaluated for their effects regarding gross and histopathology of vital organs in goat and other livestock species.

\section{Authors' Contributions}

JMS was the principle investigator and TAQ was the supervisor. TS and QAS coordinated sampling; MAA and ZAB wrote the manuscript. MS and FAS helped in statistical analysis. All authors review and approve the manuscript for publication.

\section{Acknowledgments}

There is no financial sponsor to this work. The authors are very thankful to the staff members of livestock experimental farm, Sindh Agriculture University, for support of this research. In addition, authors are grateful to the laboratory staff of the department of Physiology and Pharmacology, Sindh Agriculture University, Tandojam for the support of biochemical analysis. We also thankful, to the professor and chairman, of the Department of Pharmacology, for the technical input of this research work.

\section{Competing Interests}

The authors declare that they have no competing interests.

\section{References}

1. Dowling, P.M. (2013) Chloramphenicol, thiamphenicol and florfenicol. In: Giguere, S., Prescott, J.F., Dowling, P.M., editors. Antimicrobial Therapy in Veterinary Medicine. $5^{\text {th }}$ ed. Wiley-Blackwell, Hoboken, NJ. p269-278. 
2. Elitok, O.M., Elitok, B., Konak, S. and Demirel, H.H. (2015) Clinical efficacy of florfenicol on caprinepasteurellosis. Small Rumin. Res., 125: 142-145.

3. Picco, E., Diaz, D., Valtorta, S. and Boggio, J. (2001) Chronotoxicology of florfenicol. Chronobiol. Int., 18: 567-572.

4. Sams, R.A. (1995) Florfenicol: Chemistry and metabolism of a novel broad-spectrum antbiotic. Tier. Umsch., 50(10): 703-707.

5. Switała, M., Hrynyk, R., Smutkiewicz, A., Jaworski, K., Pawlowski, P., Okoniewski, P. and Debowy, J. (2007) Pharmacokinetics of florfenicol, thiamphenicol, and chloramphenicol in turkeys. J. Vet. Pharmacol. Ther, 30: 145-150.

6. Rebecca, L., Pentecost, J., Andrew, N., Nick, A.W. and Jeffrey, L. (2013) Pharmacokinetics of florfenicol after intravenous and intramuscular dosing in llamas. Res. Vet. Sci., 95: 594-599.

7. Dongfang, H., Zhang, T., Zhang, Z., Wang, G., Wang, F., Qu, Y., Niu, Y. and Liu, S. (2014) Toxicity to the hematopoietic and lymphoid organs of piglets treated with a therapeutic dose of florfenicol. Vet. Immunol. Immunopathol., 162: 122-131.

8. Chia-Fong, W., Jui-Hung, S., Shao-Kuang, C. and ChiChung, C. (2016) Florfenicol as a modulator enhancing antimicrobial activity: Example using combination with thiamphenicol against Pasteurella multocida. Front. Microbiol., 7: 389.

9. Hismiogullari, A.A., Hismiogullari, S.E., Yavuz, O., Essiz, D. and Rahman, K. (2011) Evaluation of biochemical findings in mice exposed to thiamphenicol treatment. Afr. J. Pharm. Pharmacol., 5: 428-431.

10. McKellar, Q. and Varma, K. (1996) Pharmacokinetics and tolerance of florfenicol in equidae. Equine Vet. J., 28: 209-213.

11. Ku-Hua, J., Jian-Yun, M., Yan, Y., Zon-Ping, L., XiaoDan, M. and Hao, C. (2009) The impact of different dose florfenicol on blood biochemical indexes in pigs and antibody against classical swine fever virus. Chin. J. Vet. Sci., 29: 1586-1589.

12. Ola, H., Fatma, A. and Ashraf, A. (2014) Effects of florfenicol on the immune responses and the interferon-inducible genes in broiler chickens under the impact of $E$. coli infection. Vet. Res. Commun., 38: 51-58.

13. Shalaby, A., Khattab, Y. and Rahman, A.A. (2006) Effects of garlic (Allium sativum) and chloramphenicol on growth performance, physiological parameters and survival of Nile tilapia (Oreochromis niloticus). J. Venom. Anim. Toxins Trop. Dis., 12: 172-201.

14. Treves-Brown, K.M. (2013) Applied Fish Pharmacology. Vol. 3. Springer Science \& Business Media, Dordrecht.

15. Salomon, L., Levu, S., Deray, G., Launay-Vacher, V., Brücker, G. and Ravaud, P. (2003) Assessing residents prescribing behavior in renal impairment. Int. J. Qual. Health Care, 15: 235-240.

16. Brophy, K.M., Scarlett-Ferguson, H., Webber, K.S.,
Abrams, A.C. and Lammon, C.B. (2010) Clinical Drug Therapy for Canadian Practice. Lippincott Williams \& Wilkins, Philadelphia, PA.

17. Holmes, K., Bedenice, D. and Papich, M.G. (2012) Florfenicol pharmacokinetics in healthy adult alpacas after subcutaneous and intramuscular injection. J. Vet. Pharmacol. Ther., 35: 382-388.

18. Liu, K.Y., Li, X.X., Teng, H., Li, S.B., Guo, J.Y., Li, D.M. and $\mathrm{Hu}$, Y.P. (2009) Toxicity of florfenicol to immune organs and its effect on physical and chemical characteristics of muscle in mice. J. Anhui Sci. Technol. Univ., 23: 6-10.

19. Halliwell, W. (1981) Serum chemistry profiles in the health and disease of birds of prey. Recent Advances in the Study of Raptor Diseases. Chiron Publications Ltd., Keighley, UK. p111-112.

20. Gui-Xiang, Y., Guo-Dong, D., Ming, Z., Zhen-Ling, Z. and Zhang-Liu, C. (2000) Acute and subchronic toxicity of florfenicol on rats. Chin. J. Vet. Sci., 20: 275-278.

21. Cannon, M., Harford, S. and Davies, J. (1990) A comparative study on the inhibitory actions of chloramphenicol, thiamphenicol and some fluorinated derivatives. J. Antimicrob. Chemother., 26: 307-317.

22. Yunis, A.A., Smith, U.S. and Restrepo, A. (1970) Reversible bone marrow suppression from chloramphenicol: A consequence of mitochondrial injury. Arch. Intern. Med., 126: 272-275.

23. Zelkowitz, L., Arimura, G. and Yunis, A. (1968) Chloramphenicol and protein synthesis in mammalian cells. Transl. Res., 71: 596-609.

24. Solter, P.F. (2005) Clinical pathology approaches to hepatic injury. Toxicol. Pathol., 33: 9-16.

25. Zilva, J.F. and Mayne, P.R. (1991) Clinical Chemistry in Diagnosis and Treatment. $5^{\text {th }}$ ed. England Clays Ltd., London.

26. Center, S.A. (2007) Interpretation of liver enzymes. Veterinary clinics of North America. Small Anim. Pract., 37: 297-333.

27. Lattimer, K. and Mahaffey, E. (2003) Duncan and Prasse's Veterinary Laboratory Medicine Clinical Pathology. Iowa State University Press, Ames.

28. Guilford, W.G., Center, S.A., Strombeck, D.R., Williams, D.A. and Meyer, D.J. (1996) Strombeck's Small Animal Gastroenterology. W.B. Saunders Co., Philadelphia, PA.

29. Amacher, D.E. (1998) Serum transaminase elevations as indicators of hepatic injury following the administration of drugs. Regul. Toxicol Pharmacol., 27: 119-130.

30. Ennulat, D., Slav, M.M., Rehm, S. and Tatsuoka, K.S. (2010) Diagnostic performance of traditional hepatobiliary biomarkers of drug-induced liver injury in the rat. Toxicol. Sci., 116(2), 397-412.

31. Boone, L., Meyer, D., Cusick, P., Ennulat, D., Bolliger, A.P., Everds, N. and Bounous, D. (2005) Selection and interpretation of clinical pathology indicators of hepatic injury in preclinical studies. Vet. Clin. Pathol., 34: 182-188.

32. Fingeroth, J.D. (2000) Herpesvirus infection of the liver. Infect. Dis. Clin. North Am., 14: 689-719. 